\title{
Designing Relational The database Model For Goes System With Life Cycle The database Method
}

\author{
Hilda Hilaliyah ${ }^{1}$, Desi Novianti ${ }^{2}$, Dewi Anjani ${ }^{3}$ \\ \{Hilda.unindra@gmail.com¹, desi.novi4nti@gmail.com², dewiunindra@gmail.com ${ }^{3}$ \}
}

Dept. Education, Universitas Indraprasta PGRI, Jakarta, Indonesia ${ }^{1}$, Dept. Informatics, Universitas Indraprasta PGRI, Jakarta, Indonesia ${ }^{23}$

\begin{abstract}
Needs Educational technology at this time continues to grow, from simple applications to complex application systems. Goes application is an e-learning application which can assist elementary schools in implementing the learning process. It was created due to weaknesses in an existing e-learning system. One of them is no means of communication among teachers, students, and student parents. Through e-learning concept, the creation of an application requires the database which can ease the data storage. Therefore, to prevent from redundant the data storage, the database designing is needed using the database Life Cycle method. The final result of this research shows that conceptual designing produces entities such as teachers, students, student parents, subjects, meetings, examples, materials, answers, and notifications. Logic designing creates tables and relationship among tables using Entity Relationship Diagram. Physical designing which is the implementation of logic designing eases physical storage.
\end{abstract}

Keywords: e-learning, the database, goes, life cycle method.

\section{Introduction}

Education technology needs keep growing nowadays from simple applications to complex application systems. Educational technology is a study and practice to assist learning process and improve performance by creating, using, and managing proper technological processes and sources and is also educational media, in which technology is used as an assisting tool to make education more effective and more efficient.

Developing educational technology aims to solve learning problems as a problem for teachers and students. For example, numerous students cannot concentrate when studying so the knowledge teachers deliver cannot be processed by students. On the other hand, teachers also experience difficulties in teaching. Therefore, the knowledge they have cannot be delivered properly to students.

By utilizing educational technology, students are expected to access sources of knowledge more easily than before implementing the benefit of technology since information can be accessed through gadgets (handphone, iPad, mobile tab). Educational materials can be accessed through remote learning if it is not hampered by cost and time.

There are ways to create a simulative learning environment. Traditionally, the simulative learning environment is developed using educational audio and visual contents. In a common scenario, the combination of text, audio, video, and animation contents is implemented in

ICCSET 2018, October 25-26, Kudus, Indonesia

Copyright (C) 2018 EAI

DOI 10.4108/eai.24-10-2018.2280630 
presentations and stored in an electronic format. The implementation of this content creates a simulative learning environment often called electronic learning or e-learning. E-learning is also one of the educational technologies.

E-learning has significantly grown as a means of education since technology has developed for years. The interesting point is that there are more measures to develop technology than to understand the learning needs and styles of each educational participants and instructional design. [1].

Goes Application is an e-learning application which can assist elementary schools in implementing the learning process. It was created due to weaknesses in an existing e-learning system. One of which is no means of communication among teachers, students, and student parents. With the e-learning concept, the creation of an application must have the database which can ease the data storage.

The database management or DBMS is a collection of programs which manage the database structures and control access to the data stored in the database. DBMS provides benefits including improving the data sharing. DBMS helps to create an environment in which end-users have better access to more and better the data. The other benefit is to improve the data security. The more users access the data, the higher the data security violation risks will be. Companies invested much time, effort, and money to ensure corporate the data is used correctly.[2] Therefore, to prevent from redundant the data storage, the database designing is needed.

\section{Method}

The methods used in this research are the data collection method, analysis method, and the database designing method. The techniques used in this the data collection method include interview, document study, observation, and literary study. [3] Interview is performed in parts which will use the proposed the database system. The questions to be asked will be prepared before conducting the direct interview. It will be the combination of closed and opened questions. [4]

To obtain the data and information about user needs comprehensively, document collection is also conducted. Moreover, direct observation is also performed to partners [5].

There are three phases in creating the database model design namely Conceptual The database Design, Logic The database design, dan Physical The database design [5]. Conceptual The database Design is a process to create a model from information used in companies which are independent of the overall physical aspect. The data model is developed using information in user needs specifications and is the source of information for the logic design phase. Meanwhile, Logic The database Design is a process to create a model from the information used in companies based on particular the data models but is independent against certain DBMS and another physical aspect, for example relational. Conceptual the data model previously made is revised and re-mapped into the logical the data model. Physical The database Design is a process to produce the database implementation description in secondary storage. It aims to describe storage structures and access methods used to reach efficient access against the data. In other words, physical design is a creative method to reach certain DBMS. [6]

DBLC (The database Life Cycle) is a method explaining the life cycle of the database. This DBLC will keep returning to the initial point since the database to be made will certainly need revision based on the development. DBLC processes are divided into three phases namely conceptual, logic, and physical the database designing[7]. 
Conceptual the database designing develops the data model used in a company, independent from all physical considerations. Logic the database designing designs the data model used in a company based on the specific the data model. Physical the database designing produces the database implementation description in secondary storage, describes the basic relationship, file organization, and the index used to reach efficient access to the data and every integrity obstacle related to security measures. [8]

\section{Result And Discussion}

Initially, a designer will ask several questions to obtain detailed information like to what extent e-learning system is currently running and its weaknesses.

From interviews, partners' needs can be concluded as follows: Partners need an application which not only supports learning but also serves as a means of communication among teachers, students, and student parents. For example, teachers give homework which can directly be known by student parents so students cannot say that their teachers do not give homework. Due to the needs, Goes application was created.

Goes application needs the data storage, then the data designing is needed so the data can be accessed quickly and will not be redundant. In the database designing for Goes application, there are several phases to be performed namely conceptual, logic, and physical the database designing.

\subsection{Conceptual the database designing}

The purpose of the conceptual design phase is to develop a conceptual model based on the requirements previously identified but closer to a final physical model. The conceptual model often used is called an entity model. The entity is basically a person, place, or matters whose information will be stored. According to the provided information, a designer can initiate the database logic design by identifying initial entities shown in table 1.

Table 1. Entities in Goes application.

\begin{tabular}{|c|c|c|}
\hline Entity Names & Entity Information & Information \\
\hline Teacher & $\begin{array}{l}\text { Containing information } \\
\text { about teachers. }\end{array}$ & $\begin{array}{l}\text { A teacher can upload several subjects, a } \\
\text { teacher delivers a notification. }\end{array}$ \\
\hline Student Parents & $\begin{array}{l}\text { Containing information } \\
\text { about student parents. }\end{array}$ & A student parent has a student. \\
\hline Student & $\begin{array}{l}\text { Containing information } \\
\text { about the student. }\end{array}$ & A student can download countless subjects. \\
\hline Subject & $\begin{array}{l}\text { Containing information } \\
\text { about subjects. }\end{array}$ & $\begin{array}{l}\text { Numerous subjects can be downloaded by } \\
\text { students and a guardian, and a subject } \\
\text { consists of numerous meetings. }\end{array}$ \\
\hline Meeting & $\begin{array}{l}\text { Containing information } \\
\text { about learning meeting } \\
\text { schedules. }\end{array}$ & $\begin{array}{l}\text { A meeting may consist of numerous } \\
\text { materials, many examples, and an exercise. }\end{array}$ \\
\hline Example & $\begin{array}{l}\text { Containing information } \\
\text { about examples of } \\
\text { subjects' questions. }\end{array}$ & Numerous examples from a meeting. \\
\hline
\end{tabular}




\begin{tabular}{|c|c|c|}
\hline Entity Names & Entity Information & Information \\
\hline Material & $\begin{array}{l}\text { Containing information } \\
\text { about materials of } \\
\text { subjects' questions. }\end{array}$ & Numerous materials from a meeting. \\
\hline Exercise & $\begin{array}{l}\text { Containing information } \\
\text { about exercises of } \\
\text { subjects' questions. }\end{array}$ & An exercise consists of a meeting. \\
\hline Answer & $\begin{array}{l}\text { Containing information } \\
\text { about answers to subjects' } \\
\text { questions. }\end{array}$ & An exercise consists of an answer. \\
\hline Notification & $\begin{array}{l}\text { Containing information } \\
\text { about notifications about } \\
\text { subjects' } \\
\text { exercises. }\end{array}$ & $\begin{array}{l}\text { A notification will be delivered to numerous } \\
\text { students and student parents. }\end{array}$ \\
\hline
\end{tabular}

The entities identify attributes for each entity which can be seen in table 2 .

Table 2. The Identity of an entity.

\begin{tabular}{|c|c|c|}
\hline Entities Name & Atribut & Domain \\
\hline \multirow[t]{7}{*}{ Teacher } & Kd_guru & the data type is a string, character length is 8 \\
\hline & Nm_Guru & the data type is a string, character length is 50 \\
\hline & Tgl_Lahir & the data type is the date, format YY-YY-YYYY \\
\hline & Stat_Guru & the data type is a char, character length is 1 \\
\hline & Jk_Guru & the data type is a char, character length is 1 \\
\hline & Pend_Guru & the data type is a string, character length is 20 \\
\hline & Pass_Guru & the data type is a string, character length is 8 \\
\hline \multirow[t]{4}{*}{ Student Parents } & Kd_WS & the data type is a string, character length is 6 \\
\hline & Nm_WS & the data type is a string, character length is 50 \\
\hline & Pass_WS & the data type is a string, character length is 8 \\
\hline & No_Tlp & the data type is a string, character length is 13 \\
\hline \multirow[t]{7}{*}{ Student } & Kd_Siswa & the data type is a string, character length is 6 \\
\hline & Nn_Siswa & the data type is a string, character length is 50 \\
\hline & TTL_Siswa & the data type is the date, format YY-YY-YYYY \\
\hline & JK_Siswa & the data type is a char, character length is 1 \\
\hline & No_Telp & the data type is a string, character length is 13 \\
\hline & Pass_Siswa & the data type is a string, character length is 8 \\
\hline & Nm_WS & the data type is a string, character length is 50 \\
\hline \multirow[t]{2}{*}{ Subject } & Kd_MP & the data type is a string, character length is 6 \\
\hline & Nm_MP & the data type is a string, character length is 50 \\
\hline \multirow[t]{2}{*}{ Meeting } & Kd_Pertemuan & the data type is a string, character length is 6 \\
\hline & Nm_Pertemuan & the data type is a string, character length is 50 \\
\hline \multirow[t]{3}{*}{ Example } & Kd_cth & the data type is a string, character length is 6 \\
\hline & Nm_Cth & the data type is a string, character length is 50 \\
\hline & File_cth & the data type is a string, character length is 50 \\
\hline \multirow[t]{3}{*}{ Material } & Kd_Materi & the data type is a string, character length is 6 \\
\hline & Nm_Materi & the data type is a string, character length is 50 \\
\hline & File_Materi & the data type is a string, character length is 50 \\
\hline \multirow[t]{3}{*}{ Exercise } & Kd_Latihan & the data type is a string, character length is 6 \\
\hline & Nm_Latihan & the data type is a string, character length is 50 \\
\hline & File_Latihan & the data type is a string, character length is 50 \\
\hline \multirow{3}{*}{ Answer } & $\mathrm{Kd}$ Jwb & the data type is a string, character length is 6 \\
\hline & $\mathrm{Nm}$ Jwb & the data type is a string, character length is 50 \\
\hline & File Jwb & the data type is a string, character length is 50 \\
\hline
\end{tabular}




\begin{tabular}{lll}
\hline Entities Name & \multicolumn{1}{c}{ Atribut } & \multicolumn{1}{c}{ Domain } \\
\hline Notification & Kd_Notif & the data type is a string, character length is 6 \\
& Tgl_notif_awal & the data type is the date, format YY-YY-YYYY \\
& Tgl_notif_akhir & the data type is the date, format YY-YY-YYYY \\
& Ket_Notif & the data type is a string, character length is 250 \\
\hline
\end{tabular}

\subsection{Logic the database designing}

The next step is to create an Entity Relationship Diagram (ERD) to relate the tables and ease the database coding. The relationship between tables can be seen in image 2. Fig, 1 shows that 9 tables are made and they correlate with each other.

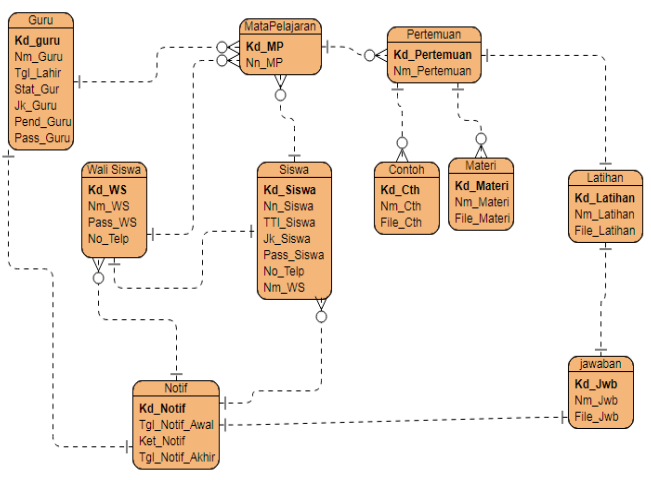

Fig. 1. ERD of Goes Application.

\subsection{Physical the database designing}

In this phase, tables will be transformed to DBMS type to ease physical storage. The form of Goes' physical the database designing is shown in tables 3 to 12 .

Table 3. Teacher.

\begin{tabular}{cccc}
\hline No & Field Name & Type & Size \\
\hline 1. & Kd_guru* & Varchar & 8 \\
2. & Nm_Guru & Varchar & 50 \\
3. & Tgl_Lahir & The date & - \\
4. & Stat_Guru & Char & 1 \\
5. & Jk_Guru & Char & 1 \\
6. & Pend_Guru & Varchar & 20 \\
7. & Pass_Guru & Varchar & 8 \\
\hline
\end{tabular}

Table 4. Student Parents.

\begin{tabular}{cccc}
\hline No & Field Name & Type & Size \\
\hline 1. & Kd_WS* & Varchar & 6 \\
2. & Nm_WS & Varchar & 50 \\
3. & Pass_WS & Varchar & 8 \\
4. & No_Tlp & Varchar & 13 \\
\hline
\end{tabular}


Table 5. Student.

\begin{tabular}{cccc}
\hline No & Field Name & Type & Size \\
\hline 1. & Kd_Siswa* & Varchar & 6 \\
2. & Nn_Siswa & Varchar & 50 \\
3. & TTL_Siswa & The date & - \\
4. & JK_Siswa & Char & 1 \\
5. & No_Telp & Varchar & 13 \\
6. & Pass_Siswa & Varchar & 6 \\
7. & Nm_WS & Varchar & 50 \\
\hline
\end{tabular}

Table 6. Subject.

\begin{tabular}{cccc}
\hline No & Field Name & Type & Size \\
\hline 1. & Kd_MP* & Varchar & 6 \\
2. & Nm_MP & Varchar & 50 \\
\hline
\end{tabular}

Table 7. Meeting.

\begin{tabular}{cccc}
\hline No & Field Name & Type & Size \\
\hline 1. & Kd_Pertemuan* & Varchar & 6 \\
2. & Nm_Pertemuan & Varchar & 50 \\
\hline
\end{tabular}

Table 8. Example.

\begin{tabular}{cccc}
\hline No & Field Name & Type & Size \\
\hline 1. & Kd_cth* & Varchar & 6 \\
2. & Nm_Cth & Varchar & 50 \\
3. & File_cth & Varchar & 50 \\
\hline
\end{tabular}

Table 9. Material.

\begin{tabular}{clcc}
\hline No & Field Name & Type & Size \\
\hline 1. & Kd_Materi* & Varchar & 6 \\
2. & Nm_Materi & Varchar & 50 \\
3. & File_Materi & Varchar & 50 \\
\hline
\end{tabular}

Table 10. Exercise.

\begin{tabular}{cccc}
\hline No & Field Name & Type & Size \\
\hline 1. & Kd_Latihan* & Varchar & 6 \\
2. & Nm_Latihan & Varchar & 50 \\
3. & File_Latihan & Varchar & 50 \\
\hline
\end{tabular}

Table 11. Answer.

\begin{tabular}{cccc}
\hline No & Field Name & Type & Size \\
\hline 1. & Kd_Jwb* & Varchar & 6 \\
2. & Nm_Jwb & Varchar & 50 \\
3. & File_Jwb & Varchar & 50 \\
\hline
\end{tabular}


Table 12. Notification.

\begin{tabular}{clll}
\hline No & \multicolumn{1}{c}{ Nama Field } & \multicolumn{1}{c}{ Type } & \multicolumn{1}{c}{ Size } \\
\hline 1. & Kd_Notif* & Varchar & 6 \\
2. & Tgl_notif_awal & The date & - \\
3. & Tgl_notif_akhir & The date & - \\
4. & Ket_Notif & Varchar & 250 \\
\hline
\end{tabular}

\subsection{Username designing}

Logging in this application requires a username. To ease administrator in processing the database, an appropriate username is designed. For Teacher Login, they will obtain NIP which is a unique code not based on their NIP but the NIP created by the system. Terms of NIP's unique code for teachers:

1) Consisting of 8 digits : $X X X X X X X X$

2) First digit: $X-X X X X X$ shows the categories of the teacher.

Table 13. Teacher's Username.

\begin{tabular}{ll}
\hline \multicolumn{1}{c}{ Category Codes } & \multicolumn{1}{c}{ Information } \\
\hline 1 & Principal \\
2 & Classroom Teacher \\
3 & Subject Teacher \\
\hline
\end{tabular}

3) Second to fifth digits : $X-X X X X-X X X$ shows month and year when they initially serve as teachers in schools. For example, 1 August 2014 will be 0814.

4) Fourth digit: $X X X X X-X-X X$ is the information of the teachers with the following terms:

a. The Principal is filled with 0

b. The Classroom teacher is filled with the classroom they manage

c. Subject teacher is filled based on their subjects' codes:

English Language : A, PJOK : B, SBK : C, PLKJ : D

5) The last 2 digits : X X X X X X - X X shows registration number (teachers' names will be sorted based on alphabets).

For Student/Student Parents Login, they will obtain NIS which is a unique code, not their NIS but the NIS created by the system. Terms of student NIS' unique codes:

1) Consisting of 6 digits : $X X X X X X$

2) First digit: $X-X X X X X$ shows the categories of student.

Table 14. Student and Student Parents Username Table

\begin{tabular}{ll}
\hline Category Codes & Information \\
\hline 4 & Student \\
5 & Student Parent \\
\hline
\end{tabular}

3) Second and third digits : $X-X X-X X X$ shows the year when they are registered as students at schools. For example, 2014 will be 14.

4) The last 3 digits : X X X - X X X shows registration number (Students' names will be sorted based on alphabets). 


\section{Conclusion}

This research produces the database design used to develop Goes application. Conceptual designing creates entities namely the teacher, student, student parents, subject, meeting, example, material, answer, and notification. Logic designing creates tables and relationship among tables using ER-D. Physical designing is the implementation of logic designing to ease physical storage.

\section{Suggestion}

The update of Goes from an application to a system will make the database used more complex in which business process understandings will be greater and more detailed.

\section{References}

[1] M. S. El-Seoud and M. M. El-Khouly, "E-Learning and Students' Motivation: A Research Study on the Effect of E-Learning on Higher Education," iJET, pp. 20-26, 2014.

[2] C. Coronel and S. Morris, "The database System Design, Implementation and Management 12e. United State of America." Cengage Learning, 2016.

[3] Indrajani, Designing The database All in 1. Perancangan Basis The data All in 1. Jakarta: Elex Media Computindo.

[4] T. Connolly and C. Begg, "The database System: A Practical Approach to design, Implementation, and Management (5th ed.)." England: Pearson Education, 2010.

[5] Wihendro, Indrajani, and Safan, "Conceptual design of clinical the database 24 hours. Rancang bangun konseptual basis the data klinik 24 jam," in Seminar Nasional Teknologi Informasi \& Multimedia 2013, 2013.

[6] Indarjani, "Designing a Spatial The database Monitoring 24 Hour Clinic Deployment In Jakarta. Rancang Bangun Basis The data Spasial Pemantauan Penyebaran Klinik 24 Jam Di Dki Jakarta." ComTech, pp. 1368-1377, 2013.

[7] Prasetya w. s, "Designing Relational The database Model With Life Cycle The database Method. Perancangan Model Basis data Relasional Dengan Metode The database Life Cycle," in Seminar Internasional Informatika (SNIF), 2015, pp. 91-98.

[8] Laudon, Kenneth, Laudon, and J. P, "Management Information Systems: Managing The Digital Firm, 14th edition.” Prentice Hall, New Jersey, 2016. 